\title{
Жуковская И.Е.
}

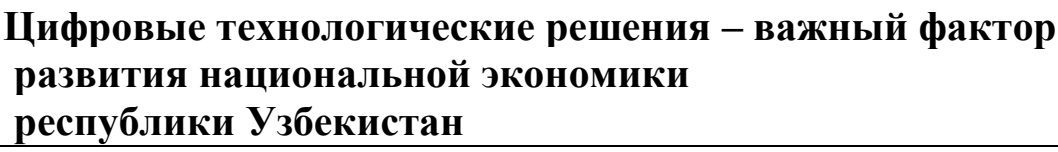

Ташкентский государственный экономический университет, проспект Ислама Каримова, 49, Ташкент, 100003, Узбекистан

e-mail: irishka.165@mail.ru

\begin{abstract}
Аннотация
В настоящей статье показано, что цифровая трансформация мировой экономической системы немыслима без эффективного применения цифровых технологических решений в деятельности экономических объектов. В результате исследований, проведенных автором, выявлены основные показатели формирования цифровой экономики в Республике Узбекистан и их влияние на эффективное развитие отраслей и сфер национальной экономики в соответствии с разработанной в стране нормативно-правовой базой. Доказано, что цифровые технологические решения оказывают прогрессивное воздействие на развитие отраслей и сфер национальной экономики.
\end{abstract}

Ключевые слова: цифровые технологии, экономическое и социальное развитие, оптимизация, эффективность, прогресс, инновации, передовые информационно-коммуникационные технологии, конкурентоспособность.

Информация для цитирования: Жуковская И.Е. Цифровые технологические решения - важный фактор развития национальной экономики Республики Узбекистан // Научный результат. Экономические исследования. 2021. Т. 7. № 1. C. 31-40. DOI: 10.18413/2409-1634-2021-7-1-0-4

\section{Irina E. Zhukovskaya}

Digital technological solutions - an important factor in the development of the national economy of the republic of Uzbekistan

Tashkent State University of Economics, 49 Islam Karimov Avenue,

Tashkent, 100003, Uzbekistan

e-mail: irishka.165@mail.ru

\begin{abstract}
This article shows that the digital transformation of the world economic system is inconceivable without the effective use of digital technological solutions in the activities of economic objects. As a result of the research carried out by the author, the main indicators of the formation of the digital economy in the Republic of Uzbekistan and their impact on the effective development of industries and spheres of the national economy in accordance with the regulatory and legal framework developed in the country have been identified. It has been proven that digital technological solutions have a progressive impact on the development of sectors and spheres of the national economy.
\end{abstract}


Keywords: digital technologies; economic and social development; optimization; efficiency; progress; innovation; advanced information and communication technologies; competitiveness

Information for citation: I.E. Zhukovskaya, "Digital technological solutions are an important factor in the development of the national economy of the Republic of Uzbekistan" // Research Result. Economic Research. 2021; 7(1). 31-40. DOI: 10.18413/2409-1634-2021-7-1-0-4

\section{Введение}

Цифровая трансформация в мировом масштабе подразумевает эффективное применение инновационных технологических решений для прогрессивного развития всех отраслей и сфер экономики.

Президент Республики Узбекистан Ш. М. Мирзиеев в своем Послании Олий Мажлису от 29 декабря 2020 года отметил: «Наука и инновации создают основу для развития страны» [Послание Президента Республики Узбекистан... 29.12.20]. Кроме того, говоря об оптимизации деятельности экономических объектов на основе внедрения цифровых технологий Президент Республики Узбекистан подчеркнул, что «к концу следующего года необходимо увеличить количество видов государственных электронных услуг на 60 , доведя их до 300, а долю дистанционных услуг не менее чем до 60 процентов» [Послание Президента Республики Узбекистан... 29.12.20].

Опыт показывает, что в современный период на всем мировом пространстве все шире развиваются цифровые технологии, такие как робототехника, интеллектуальные и аддитивные технологии, технологии открытых и больших данных, виртуальной и дополнительной реальности, блокчейн, разрабатываются и успешно функционируют в отраслях и сферах экономики различные технологические платформы.

Для развития цифровой экономики в Республике Узбекистан создана прочная нормативно-правовая база. В частности, приняты Указ Президента Республики Узбекистан № УП-6079 «Об утверждении Стратегии «Цифровой Узбекистан 2030» и мерах по ее эффективной реализации» от 5 октября 2020 года [Указ Президента Рес- публики Узбекистан № УП-6079], Указ Президента Республики Узбекистан УП №-4947 «О Стратегии действий по дальнейшему развитию Республики Узбекистан» от 7 февраля 2017 года [Указ Президента Республики Узбекистан № 4947], Указ Президента Республики Узбекистан УП №-5544 «О стратегии инновационного развития Республики Узбекистан в 2019-2021 годах» от 21 сентября 2018 года [Указ Президента Республики Узбекистан №-5544], Постановление Президента Республики Узбекистан № ПП-3832 «О мерах по развитию цифровой экономики в Республике Узбекистан» от 3 июля 2018 года [Постановление Президента Республики Узбекистан № ПП-3832], Постановление Президента Республики Узбекистан №-4642 «О мерах по широкому внедрению цифровых технологий в городе Ташкенте» от 17 марта 2020 года [Постановление Президента Республики Узбекистан №-4642] и Постановление Президента Республики Узбекистан №-4699 «О мерах по широкому внедрению цифровой экономики и электронного правительства» от 28 апреля 2020 года [Постановление Президента Республики Узбекистан №-4699].

Практика показывает, что цифровизация экономики требует от специалистов разработки новых подходов к организации сбора, обработки, передачи, распространения и хранения новых инновационных подходов, непрерывного обучения специалистов с учетом современных потребностей инновационной действительности. В этой связи материал, изложенный в настоящей статье, является актуальным и интересным. 
Целью данной статьи является доказательство положений о том, что цифровые технологии в современный период служат драйвером развития отраслей и сфер как мировой экономической системы в целом, так и национальной экономики Республики Узбекистан, в частности.

Достижение цели настоящей статьи основывается на изучении научной литературы зарубежных и отечественных авторов, выявлении положительных и проблемных аспектов в области развития цифровых технологий на мировом экономическом рынке и в отраслях и сферах национальной экономики Республики Узбекистан, а также на анализе проектов крупных компаний в области разработки и применения цифровых технологий.

Задачи, которые решены в ходе написания работы заключались в выявлении и анализе современных цифровых технологий, использующихся в отраслях и сферах экономики и их прогрессивном влиянии на их эффективное развитие.

Для решения задач, выдвинутых в настоящей статье, используются методы анализа и синтеза, работы с компьютерными сетями и интернет-источниками, монографического исследования, аналогии и стандартизации.

Практика показывает, что цифровые технологические решения сегодня все более прочно укрепляются в основе управленческих концепций, позволяют выявить преимущества и предотвратить возможные риски в экономических процессах в условиях цифровой трансформации.

\section{Основная часть}

В настоящее время цифровизация экономики является одним из важных факторов развития мировой экономической системы. Практика экономически развитых зарубежных стран, в частности таких, как США, Канада, Исландия, Южная Корея, Франция, Австралия, Дания, Великобритания, Швейцария, Норвегия, Австрия, Германия, Израиль, Нидерланды, Норвегия, Япония, показывает, что, благодаря эффективному применению передовых ИКТ и цифровых решений в отраслях и сферах экономики возможно не только оценить реальную картину развития той или иной отрасли, но и разработать долгосрочные прогнозы, целевые программы социально-экономического развития, определить индикаторы целей устойчивого развития, осуществить научные исследования, способствующие росту благосостояния населения и конкурентоспособности страны на мировом экономическом рынке.

Данное направление в науке активно изучается многими зарубежными и отечественными учеными. Так, в работе $\mathrm{N}$. Couldry и A.Powell [Couldry N., Powell A. Big data from the bottom up //Big Data \& Society, 2014] проведен многосторонний анализ понятия «большие базы данных», а также представлена историческая хронология возникновения этого понятия в научных исследованиях. Ученые В. Hesse, R. Moser и W. Riley в своих трудах pacсматривают возможности, угрозы и технологии внедрения больших данных в модернизацию социальных процессов.

Значительная часть ученых анализирует различные варианты, ограничения и угрозы, связанные с внедрением технологии больших данных в практику государственного управления [Maciejewski M. То do more, better, faster and more cheaply: Using big data in public administration //International Review of Administrative Sciences. - 2017], используя, при этом, опыт крупных корпораций, которые достаточно давно применяют это понятие для анализа рынков, поведения потребителей и других процессов.

J. Frith подчеркивает, что при использовании больших данных важно помнить об их интерпретации и коммуникации для более оптимальной обработки информации [Frith J. Big data, technical communication, and the smart city //Journal of Business and Technical Communication. - 2017].

Российские ученые также неоднократно в своих научных изысканиях обращаются к исследованию эффективного 
применения цифровых технологических решений в деятельности экономических субъектов, а также при разработке инновационных методологических решений. К их числу относятся такие исследователи, как Г.Н. Андреева, В.М. Бондаренко [Бондаренко В.М., 2018], А.М. Вендеров [Вендеров А.М., 2006], В.М. Глушков [Глушков B.M., 1982], А.И. Долженко [Долженко А.И., Шполянская И.Ю., Глушенко С.А., 2019], В.П. Косарев [Косарев В.П., 2018], С.П. Куценко, А.Н. Н.П. Тихомиров, В.В. Трофимов, Е.В. Шкарупета и др.

Вопросам внедрения цифровых технологий в отрасли и сферы национальной экономики Узбекистана посвящен круг работ таких ученых, как А. Абдугафаров [Абдугафаров А., Мухамедиева Д.Т., Мирзарахмедова А.Х., 2012], Р.Х. Алимов, Р.Х.Аюпов, Б.А. Бегалов [Бегалов Б.А., 2020], Т.Ф. Бекмуратов, А.Б. Бобожонов, С.С. Гулямов, Р.А. Дадабаева, И.Е. Жуковская [Жуковская И.Е., 2020], Ш.У. Джанадилов, Ш.Г. Одилов, Хашимходжаев Ш.И., Шермухамедов [Шермухамедов А.Т., 2018] и др.

Наряду с этим, проблемам эффективности внедрения цифровых технологий в деятельность экономических субъектов посвящены исследования целого ряда мировых компаний. К примеру, совсем недавно компания Huawei предоставила отчет за 2020 год под названием «Глобальный индекс сетевого взаимодействия». Данная компания проводит такие исследования уже в течении семи лет. Однако, впервые в 2020 году данной компанией предложено пять этапов цифровой трансформации отраслей. В частности, аналитиками вышеназванной компании выделено «пять основных этапов цифровизации:

- эффективность задач;

- функциональная эффективность;
- системная эффективность;

- организационная эффективность и гибкость;

-эффективность и устойчивость экосистемы»

[https://ictnews.uz/05/02/2021/global-index].

Кроме того, аналитики компании Huawei в своем отчете представили вывод о том, что цифровые технологические решения способствуют росту производительности труда, что в конечном итоге способствует конкурентоспособности на мировом экономическом рынке. В этой связи необходимо отметить, что в современный период в отраслях и сферах экономики, в том числе и в Узбекистане все активнее используются цифровые механизмы их развития.

Современная действительность показывает, что в настоящее время в Республике Узбекистан разработана «Дорожная карта», утвержденная в рамках Указа Президента Республики Узбекистан «Об утверждении Стратегии «Цифровой Узбекистан 2030» и мерах по ее эффективной реализации», которая предусматривает развитие следующих направлений:

- развитие системы электронного правительства»;

- развитие цифровой индустрии;

- развитие цифрового образования;

- развитие цифровой инфраструктуры [Постановление Президента Республики Узбекистан № ПП-3832].

Как свидетельствуют данные Государственного комитета Республики Узбекистан по статистике год от года в стране увеличивается количество услуг связи и информатизации (рис. 1) [www.stat.uz официальный сайт Государственного комитета Республики Узбекистан по статистике]. 


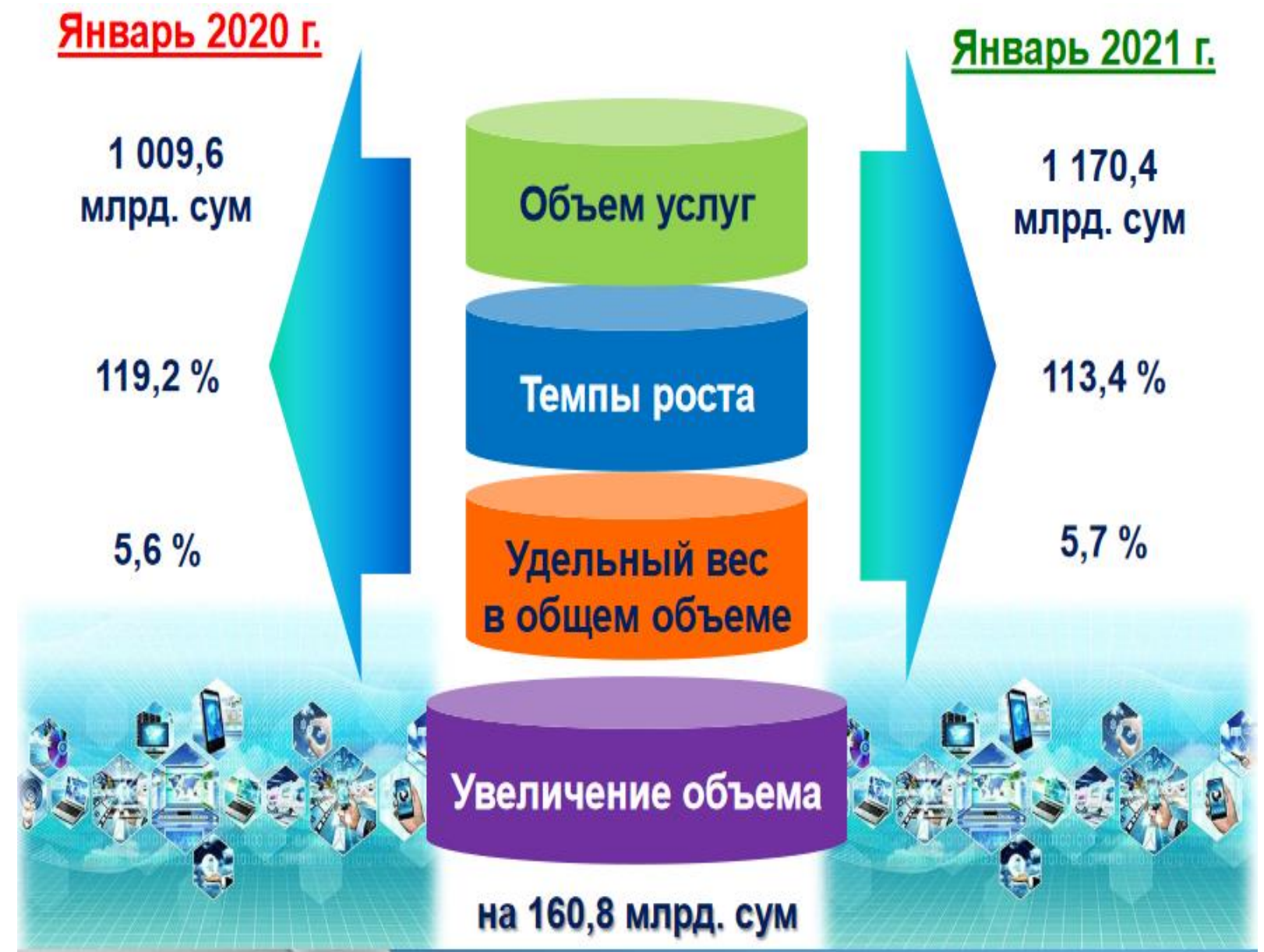

Рис. 1. Услуги связи и информатизации в Республике Узбекистан (данные за январь 2021 года)

Fig. 1. Communication and informatization services in the Republic of Uzbekistan (data for January 2021)

Вместе с тем, данные Государственного комитета Республики Узбекистан по статистике показывают, что за январь 2021 года доля телекоммуникационных услуг (услуги проводной, мобильной, спутниковой связи, сети Интернет) составила 74,8 $\%$. Как видно из рис. 2, в январе 2021 года значительные темпы роста услуг связи и информатизации в Республике Узбекистан отмечены в Ташкентской области $(130,6 \%)$, Сырдарьинской области $(117,3 \%), \quad$ Кашкадарьинской $\quad(114,9 \%)$, Джизакской $(114,5 \%)$ и Сурхандарьинской (114,5\%) областях (рис. 2).

В свою очередь, цифровизация является драйвером развития отраслей и сфер национальной экономики. В таблице представлены основные макроэкономические показатели Республики Узбекистан за последние 5 лет.

Исследования свидетельствуют о том, что основным макроэкономическим показателем является валовой внутренний продукт, характеризующий конечный результат производственной деятельности экономических единиц-резидентов, который измеряется стоимостью товаров и услуг, произведенных этими единицами для конечного использования. Темпы прироста ВВП в Республике Узбекистан по видам экономической деятельности за 2020 год (в \% к предыдущему году) представлены на рис. 3 [www.stat.uz]. 


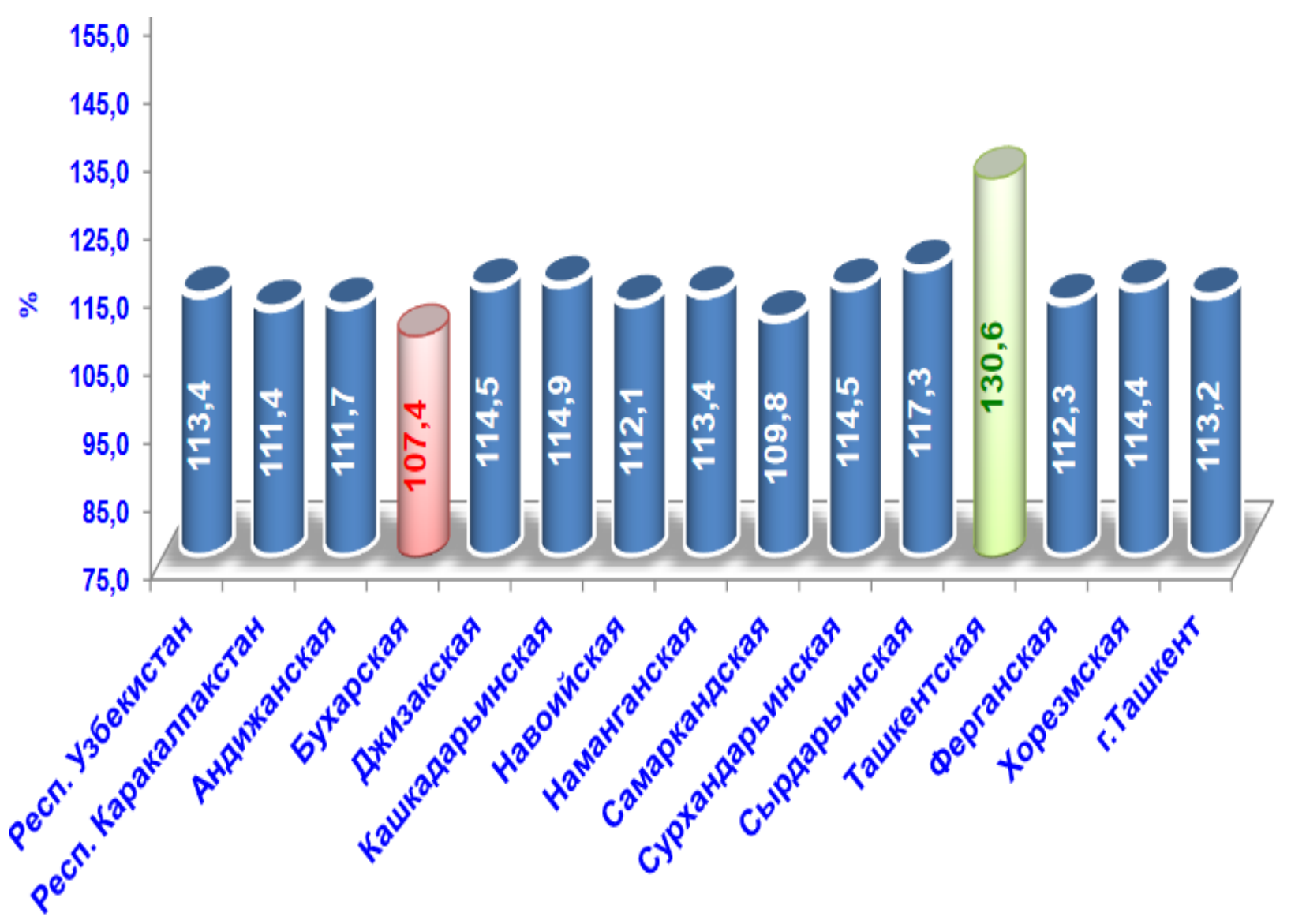

Рис. 2. Темпы роста услуг связи и информатизации в Республике Узбекистан в 2021 году, в \% к 2020 году

Fig. 2. Growth rates of communication and informatization services in the Republic of Uzbekistan in 2021, in\% by 2020

Таблица

Основные макроэкономические показатели Республики Узбекистан

Key macroeconomic indicators of the Republic of Uzbekistan

\begin{tabular}{|c|c|c|c|c|c|c|}
\hline $\begin{array}{c}\text { Наименование } \\
\text { показателя }\end{array}$ & $\begin{array}{c}\text { Единица } \\
\text { измерения }\end{array}$ & 2016 г. & 2017 г. & 2018 г. & 2019 г. & 2020 г. \\
\hline $\begin{array}{c}\text { Валовой внут- } \\
\text { ренний продукт }\end{array}$ & млрд.сум & 242495,5 & 302536,8 & 406648,5 & 511838,1 & 580203,2 \\
\hline $\begin{array}{c}\text { Промышленная } \\
\text { продукция }\end{array}$ & млрд.сум & 111869,4 & 148846,0 & 235340,7 & 331006,6 & 367078,9 \\
\hline $\begin{array}{c}\text { Потребительские } \\
\text { товары }\end{array}$ & млрд.сум & 48253,8 & 59690,4 & 83512,6 & 111494,3 & 119159,8 \\
\hline $\begin{array}{c}\text { Сельское, лесное } \\
\text { и рыбное хозяй- } \\
\text { ство }\end{array}$ & млрд.сум & 119726,7 & 154369,4 & 195103,7 & 224288,8 & 260306,8 \\
\hline Инвестиции & млрд.сум & 51232,0 & 72155,2 & 124231,3 & 189924,3 & 202000,1 \\
\hline
\end{tabular}




\begin{tabular}{|c|c|c|c|c|c|c|}
\hline $\begin{array}{c}\text { Наименование } \\
\text { показателя }\end{array}$ & $\begin{array}{c}\text { Единица } \\
\text { измерения }\end{array}$ & 2016 г. & 2017 г. & 2018 г. & 2019 г. & 2020 г. \\
\hline $\begin{array}{c}\text { Строительные } \\
\text { работы }\end{array}$ & млрд.сум & 29413,9 & 34698,0 & 54129,3 & 68854,4 & 87823,8 \\
\hline $\begin{array}{c}\text { Розничный това- } \\
\text { рооборот }\end{array}$ & млрд.сум & 88071,6 & 105229,9 & 133195,2 & 164184,2 & 194843,5 \\
\hline $\begin{array}{c}\text { Услуги, } \\
\text { всего }\end{array}$ & млрд.сум & 97050,0 & 118811,0 & 150889,8 & 190356,0 & 218853,5 \\
\hline $\begin{array}{c}\text { Внешнеторговый } \\
\text { оборот }\end{array}$ & млн.долл.США & 24232,0 & 26566,1 & 33429,9 & 42177,8 & 36299,3 \\
\hline Экспорт & млн.долл.США & 12094,6 & 12553,7 & 13990,7 & 17901,7 & 15127,7 \\
\hline Импорт & млн.долл.США & 12137,6 & 14012,4 & 19439,2 & 24276,1 & 21171,5 \\
\hline
\end{tabular}

Источник: Составлено автором на основе данных Государственного комитета Республики Узбекистан по статистике.

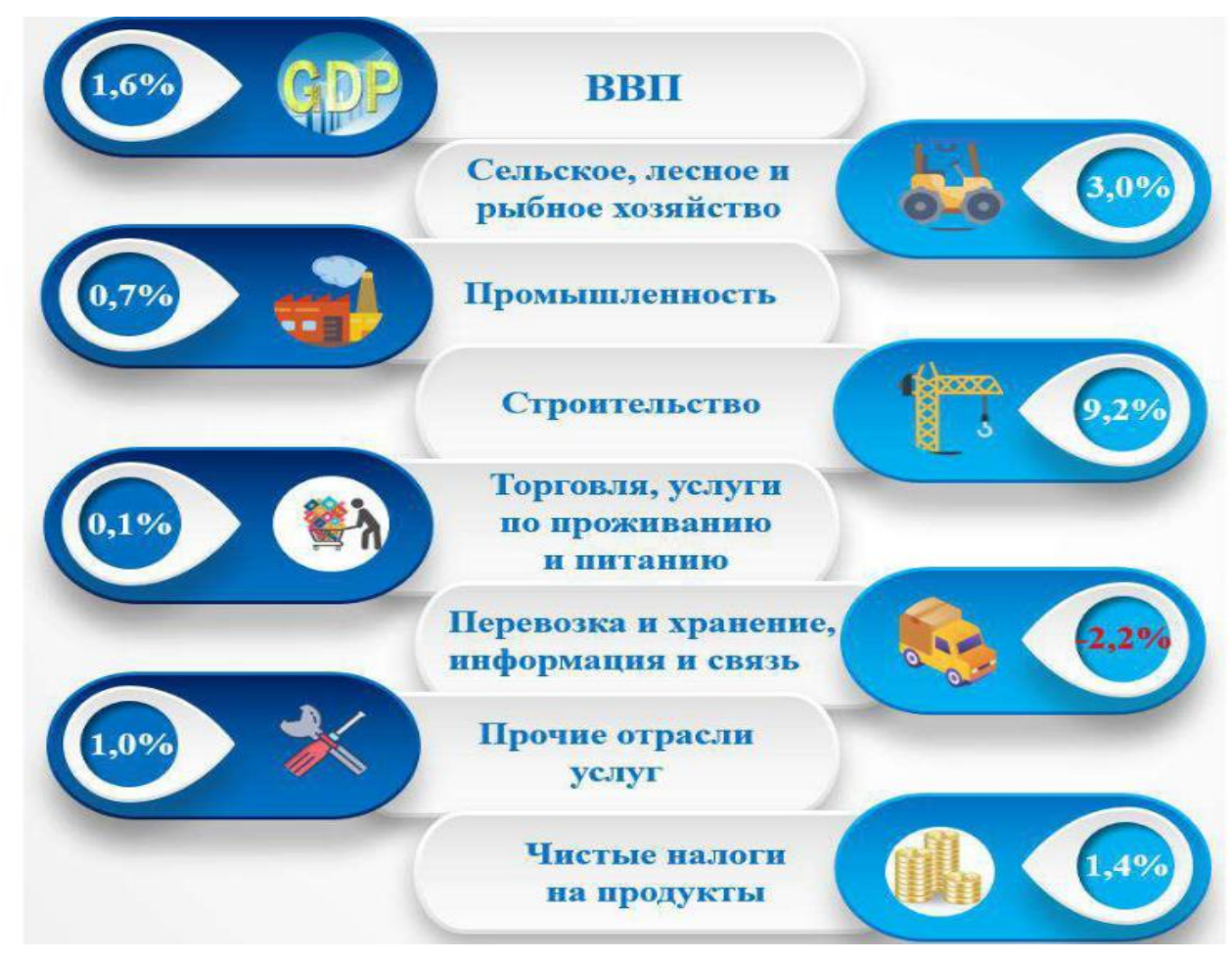

Рис. 3. Темпы прироста ВВП в Республике Узбекистан по видам экономической деятельности за 2020 год (в \% к предыдущему году)

Fig. 3. Growth rates of the Gross Domestic Product in the Republic of Uzbekistan by type of economic activity in 2020 (in\% to the previous year)

По результатам исследований можно заключить, что формирование цифровой экономики обеспечивает следующие направления развития в национальной экономике:

- создание новой информационной инфраструктуры, в частности, развитие высокоскоростного доступа к интернету, беспроводной связи, сетей $5 \mathrm{G}$ и т.д.;

- развитие сквозных цифровых технологий, в том числе, облачных и аддитивных технологий, интернет вещей, робототехники и др.; 
- трансформация общества и бизнеca, которая, в свою очередь, включает цифровую грамотность каждого отдельного гражданина и сотрудника, а также всестороннее развитие личности;

- конвергенция технологий;

- формирование и развитие новых бизнес-моделей;

- разработка и внедрение новых цифровых платформ;

- наращивание цифровой грамотности и т.д.;

- развитие и совершенствование систем информационной и кибербезопасности.

В свою очередь развитие цифровой экономики способствует развитию цифровой грамотности населения, новых цифровых инструментов, оптимальной организации коммуникационных процессов в обществе на основе использования интеллектуальных технологий, робототехники, технологии открытых и больших данных, блокчейн, разработки и внедрения различных технологических платформ.

\section{Заключение}

Настоящее исследование показывает, что в условиях цифровой трансформации мировой экономической системы, отрасли и сферы национальной экономики Республики Узбекистан все больше и больше используют потенциал цифровых технологических решений, которые способствуют достижению конкурентных преимуществ на мировом экономическом рынке. Данный подход подразумевает не только модернизацию технического оборудования, обновление программного обеспечения или интеллектуализацию производства, но и фундаментальные изменения в управленческих процессах, корпоративной культуре и внешних коммуникациях. В свою очередь, совершенствование управления способствует росту производительности труда каждого сотрудника, оптимизации информационного обмена, роботизации и интеллектуализации труда, что в конечном итоге служит достижению высоких результатов на экономическом рынке.

\section{Список литературы}

1. Послание Президента Республики Узбекистан Ш.М. Мирзиёева Олий Мажлису от 29 декабря 2020 года // Народное слово 2020 год, 30 декабря.

2. Указ Президента Республики Узбекистан № УП-6079 «Об утверждении Стратегии «Цифровой Узбекистан 2030» и мерах по ее эффективной реализации» от 5 октября 2020 года // Народное слово. - Ташкент, 2020 г., 6 октября.

3. Указ Президента Республики Узбекистан № 4947 «О Стратегии действий по дальнейшему развитию Республики Узбекистан» от 7 февраля 2017 года // Народное слово. - Ташкент, 2017 г., 8 февраля. 4. Указ Президента Республики Узбекистан №-5544 «О стратегии инновационного развития Республики Узбекистан в 2019-2021 годах» от 21 сентября 2018 года // Народное слово. Ташкент, 2018 г., 22 сентября.

5. Постановление Президента Республики Узбекистан № ПП-3832 «О мерах по развитию цифровой экономики в Республике Узбекистан» от 3 июля 2018 года // Народное слово. - Ташкент, 2018 г., 4 июля.

6. Постановление Президента Республики Узбекистан №-4642 «О мерах по широкому внедрению цифровых технологий в городе Ташкенте» от 17 марта 2020 года // Народное слово. - Ташкент, 2020 г., 18 марта.

7. Постановление Президента Республики Узбекистан №-4699 «О мерах по широкому внедрению цифровой экономики и электронного правительства» от 28 апреля 2020 года // Народное слово. - Ташкент, 2020 г., 29 апреля.

8. Бондаренко В.М., 2018. Структурная модернизация в условиях формирования цифровой экономики // МИР (Модернизация. Инновации. Развитие). 2018., Т.9.- №2: 172-191.

9. Вендеров А.М., 2006. Проектирование программного обеспечения экономических информационных систем. Учебник. М.: Финансы и статистика, 2006: 544.

10.Глушков В.М., 1982. Основы безбумажной информатики. - М.: Наука, 1982: 552.

11.Долженко А.И., Шполянская И.Ю., Глушенко С.А., 2019. Анализ качества микро - 
сервисов информационной системы на базе нечеткой модели // Прикладная информатика. 2019. - №5 (83).

12.Косарев В.П., 2018. Современные информационные технологии и услуги в коммерческом банке: учебное пособие. - М.: Финансового университета при Президенте Российской Федерации, 2018.

13.Абдугафаров А., Мухамедиева Д.Т., Мирзарахмедова А.Х., 2012. Решение нечеткой задачи привлечения инвестиций в зонах рискованного земледелия. Материалы Республиканской научно-практической конференции «Информационные технологии, системы и приборы АПК». Т.: ТАТУ, 2012: 383-387.

14.Бегалов Б.А., 2020. Сколько нас? Определит перепись // Народное слово. 24 апреля 2020 г. (Электронный ресурс http://xs.uz/ru/site/newspaper).

15.Жуковская И.Е., 2020. Основные направления совершенствования методологии применения передовых информационнокоммуникационных технологий в статистической деятельности Республики Узбекистан в условиях формирования цифровой экономики. Статистика и Экономика. 2020, 17(5): 68-80. https://doi.org/10.21686/2500-3925-2020-5-68$\underline{80 .}$

16.Шермухамедов А.Т., 2018. Инновационное развитие экономики Узбекистана: интеллектуальный потенциал. Международная научно-практическая конференция «Интеллектуальный анализ данных и цифровая экономика» в Пятигорске. Филиал РЭУ им. Г.В. Плеханова, 25-27 октября 2018.

17.Официальный портал Государственного комитета Республики Узбекистан по статистике [Электронный ресурс]. Режим доступа: http://www.stat.uz.

\section{References}

1. Message from the President of the Republic of Uzbekistan Sh.M. Mirziyoyev to the Oliy Majlis of December 29, 2020 // People's Word 2020, December 30.

2. Decree of the President of the Republic of Uzbekistan No. UP-6079 "On approval of the Strategy "Digital Uzbekistan 2030" and measures for its effective implementation" dated October 5, 2020 // Narodnoye Slovo. - Tashkent, 2020, October 6 .

3. Decree of the President of the Republic of Uzbekistan No. 4947 "On the Strategy of Ac- tions for the Further Development of the Republic of Uzbekistan" dated February 7, 2017 // People's Word. - Tashkent, 2017, February 8.

4. Decree of the President of the Republic of Uzbekistan No.-5544 "On the strategy of innovative development of the Republic of Uzbekistan in 2019-2021" dated September 21, 2018 // People's Word. Tashkent, 2018, September 22.

5. Resolution of the President of the Republic of Uzbekistan No. PP-3832 "On measures to develop the digital economy in the Republic of Uzbekistan" dated July 3, 2018 // Narodnoe Slovo. - Tashkent, 2018, July 4.

6. Resolution of the President of the Republic of Uzbekistan No.-4642 "On measures for the widespread introduction of digital technologies in the city of Tashkent" dated March 17, 2020 // Narodnoye Slovo. - Tashkent, 2020, March 18.

7. Resolution of the President of the Republic of Uzbekistan No.-4699 "On measures for the widespread introduction of the digital economy and electronic government" dated April 28, 2020 // Narodnoye Slovo. - Tashkent, 2020, April 29.

8. Bondarenko V.M. Structural modernization in the context of the formation of the digital economy // MIR (Modernization. Innovation. Development). 2018.T.9. \# 2. Pp. 172-191.

9. Venderov A.M., (2006). Software design for economic information systems. Textbook. Moscow: Finance and Statistics, 2006.- 544 p.

10. Glushkov V.M., (1982). Fundamentals of Paperless Informatics. - M.: Nauka, 1982. $552 \mathrm{p}$.

11. Dolzhenko A.I., Shpolyanskaya I.Yu., Glushenko S.A., (2019). Analysis of the quality of micro - services of an information system based on a fuzzy model // Applied Informatics. 2019. No. 5 (83).

12. Kosarev V.P., (2018). Modern information technologies and services in a commercial bank. Textbook. allowance. - M.: Publishing House of the Financial University under the President of the Russian Federation, 2018.

13. Abdugafarov A., Mukhamedieva D.T., Mirzarakhmedova A.Kh., (2012). Solving the fuzzy problem of attracting investment in risky farming zones. Materials of the Republican Scientific and Practical Conference "Information Technologies, Systems and Devices of the Agroindustrial Complex". T.: TATU, 2012.S. 383-387.

14. Begalov B.A., (2020). How many are we? Determine the census // People's word. April 
24, $2020 \quad$ (Electronic resource http://xs.uz/ru/site/newspaper).

15. Zhukovskaya I.E., (2020). The main directions of improving the methodology for the application of advanced information and communication technologies in the statistical activities of the Republic of Uzbekistan in the context of the formation of the digital economy. Statistics and Economics. 2020; $17 \quad$ (5): 68-80. https://doi.org/10.21686/2500-3925-2020-5-6880 .

16. Shermukhamedov A.T., (2018). Innovative development of the economy of (Uzbekistan: intellectual potential. International scientific and practical conference "Data mining and digital economy" in Pyatigorsk. Branch of the PRUE G.V. Plekhanov, October 25-27, 2018.

17. Official portal of the State Committee of the Republic of Uzbekistan on Statistics [Electron. resource]. Access mode: http://www.stat.uz.
Информация о конфликте интересов: автор не имеют конфликта интересов для декларации.

Conflicts of Interest: the author has no conflict of interest to declare.

Жуковская И.Е., доктор экономических наук, профессор кафедры «Цифровая экономика и информационные технологии» Ташкентского государственного экономического университета, ТГЭУ, (г. Ташкент, Узбекистан).

I.E. Zhukovskaya, Doctor of Economics (DSc), Professor at the Department of Digital Economy and Information Technologies, Tashkent State Economic University, TSUE, (Tashkent, Uzbekistan). 